\title{
Bivariate representation of population density using public and private drinking and wastewater infrastructure
}

\author{
Georgianna Strode $^{\mathrm{a}}{ }_{*}$, Victor Mesev $^{\mathrm{a}}$ \\ ${ }^{a}$ Florida State University, gstrode@fsu.edu,vmesev@fsu.edu \\ * Corresponding author
}

\begin{abstract}
Drinking and wastewater infrastructure consists of both public and private usage. On each property parcel, drinking water can be privately provided by a well or publicly provided through a municipality. Wastewater can be a private septic tank or a public sewer. Property parcels can use all private, all public, or a combination of public and private solutions. It is important for planners and city officials to have knowledge of these systems, and it is also important to know the number of people using each type of infrastructure to prioritize resources and plan for future expansions. Visualizing the complexity of these data using separate univariate maps is aesthetically inferior involving back and forth comparisons. Further, the univariate maps represent land parcels only and do not capture the population that is using each type of water infrastructure. Our research develops a single bivariate map that facilitates the visualization of population using both public and private drinking and wastewater solutions simultaneously. The bivariate map is tended for use by planners, city officials, environmentalists, and others interested in the visualization of the spatial patterns of water infrastructure within one complete map.
\end{abstract}

Keywords: bivariate, gridded map, water infrastructure, sewer, well

\section{Introduction}

\subsection{The Visualization Challenge}

As a public health concern, it is important for officials to have accurate information on the spatial locations of public and private infrastructure on water systems, as well as estimates on the number of people using them. In particular, private wells can become contaminated and private sewers must be inspected and maintained to protect the environment from pollution. Public infrastructure costs of drinking water and using sewers can be affected by spatial growth and development patterns (Spier and Stephenson, 2002). Planners may ask, "if we extend this sewer line, how many people can we include?" After a disaster, first responders may ask, "how many people in this area use well water?" The answers may not be apparent using common univariate mapping techniques because they do not typically contain information on population counts. Further, synthesizing relationships between public and private infrastructure will be problematic as the spatial locations of drinking and wastewater locations are typically mapped independently on separate maps.

Our work demonstrates a bivariate solution to convey the relationships between public and private infrastructure as well as provide population estimates using each type of water usage. We demonstrate a method to solve the aforementioned problems and visualize all data on a single bivariate map. The focus of the map is redirected from simply locating the type of infrastructure to the human population using the infrastructure type, thereby quickly facilitating the measurement of population counts and infrastructure usage.

\subsection{Study Area}

Our study area is the state of Florida, United States of America. We apply our method to the full state and demonstrate several geographic areas in order to show that our method captures differences in population densities and mixed water infrastructures. Local cities and counties control their drinking and wastewater utilities and our method reveals varying data patterns resulting from local planning decisions within the state of Florida.

\subsection{Data Investigation}

In Florida, the Department of Health provides a centralized geographic information system (GIS) dataset that links each built land property parcel in the state with a drinking water source (public water or private well) as well as wastewater treatment methods (central sewer or onsite private septic system) (FLWMI). This dataset is the basis for our bivariate map.

Existing water infrastructure maps at the property parcel scale typically show only one type of water infrastructure, raising the need for multiple maps. Figures 1 and 2 are examples of existing types of water infrastructure mapping. Figures 1 and 2 map the land parcels of Alachua County, in north Florida as an example of the use of public and private drinking and wastewater. Two univariate maps are typically necessary to show both 
drinking and wastewater, causing the map reader to look back and forth between the maps. Figure 3, also an existing type of water infrastructure map, synthesizes public and private water usage, showing the relationships using only one (bivariate) map. However, Figure 3 falls short because it lacks a one-to-one relationship between public and private infrastructures. It is not possible to measure the infrastructures of the parcels with combined methods. Also, Figure 3 does not show population counts which are an important further indicator of infrastructure usage. It is insufficient to use land area as a basis for population estimation as large parcels might have few residents and smaller parcels may have many. Without population estimates, it is not possible to measure the number of people using each type of infrastructure.

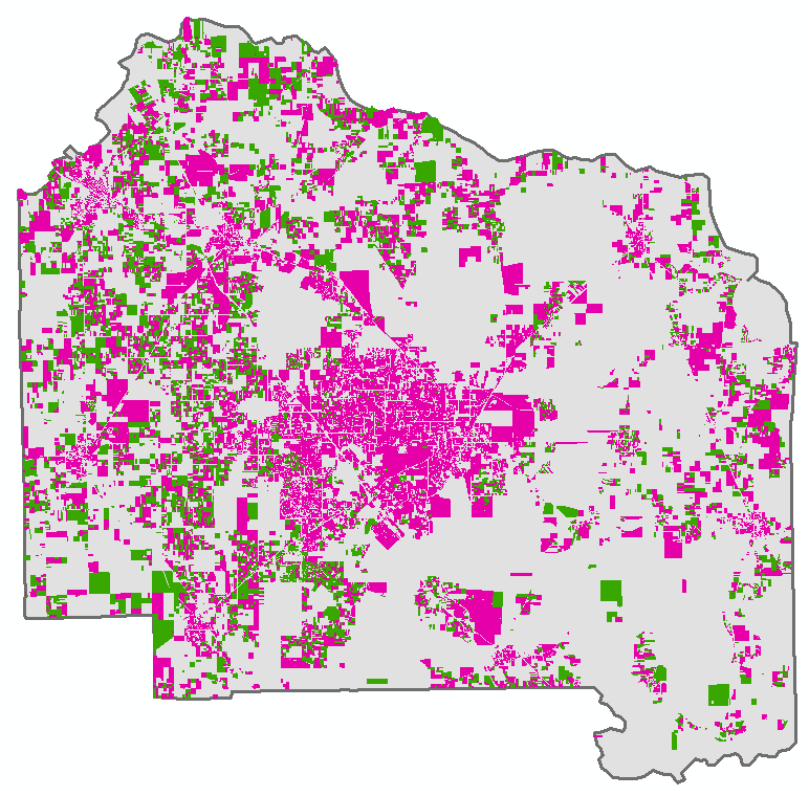

Figure 1. Existing Map - Univariate map of Alachua County property parcels and corresponding drinking water solutions. Parcels shown in pink use public drinking water and parcels shown in green use private wells.

\section{Data and Methods}

\subsection{Data}

Data from the Florida Water management Inventory (FLWMI) concatenates water infrastructure to the statewide GIS property appraiser parcel data. Each record represents a property parcel and contains information indicating the type of infrastructure (public or private) for both drinking and wastewater (FLWMI, 2021). The population data are estimations for each land parcel derived from Strode's (2018) dasymetric methods. Figure 4 shows the resulting population estimates at the property parcel scale, and Figure 5 illustrates the same estimates aggregated to a 1-kilometer grid tessellation.

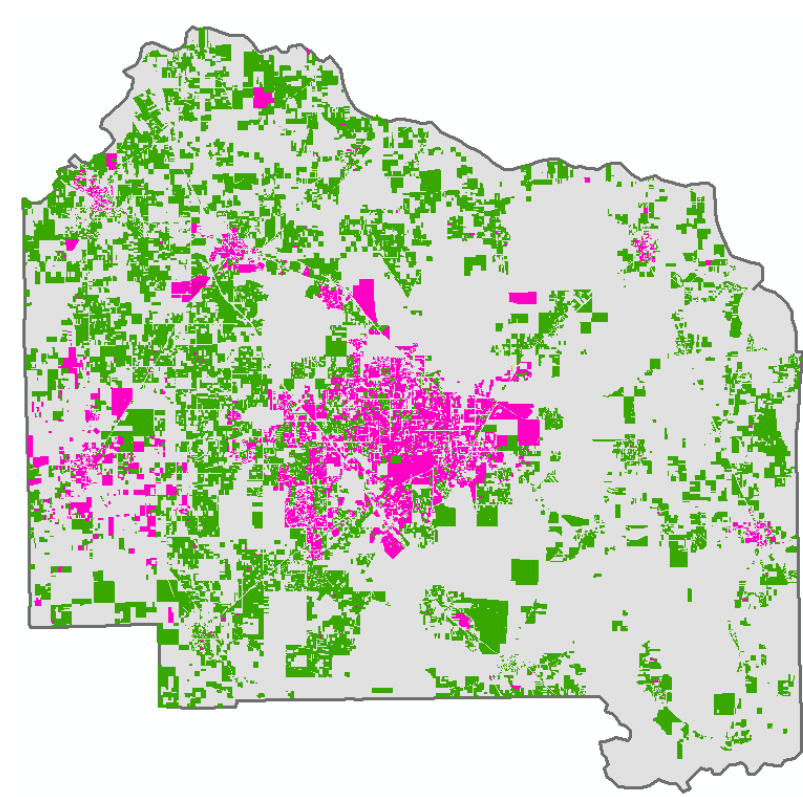

Figure 2. Existing Map - Univariate map of Alachua County property parcels and corresponding wastewater infrastructure. Parcels shown in pink use a public sewer and parcels shown in green use a private septic tank system.

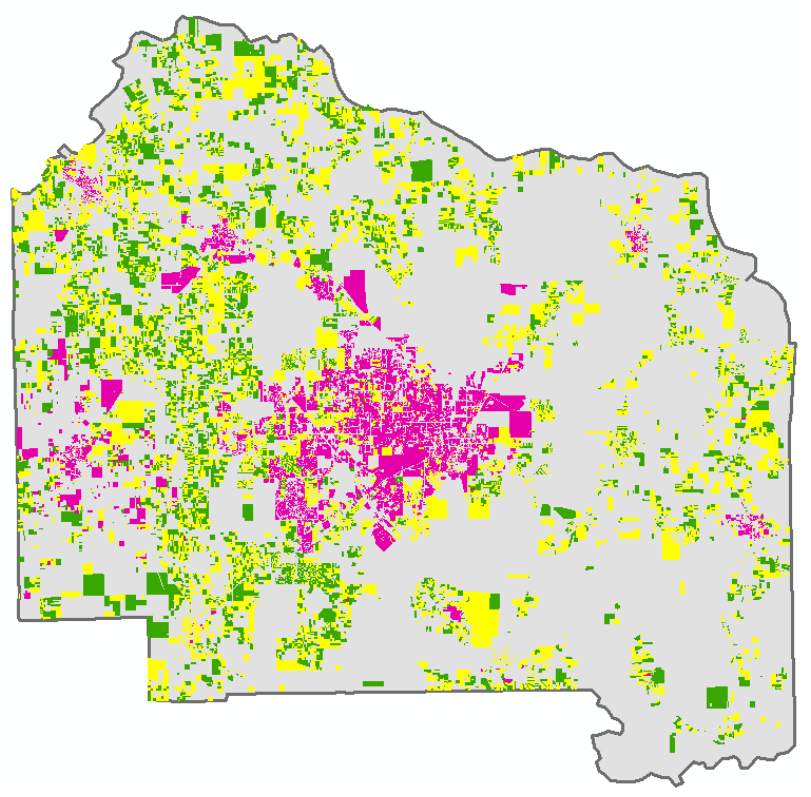

Figure 3. Existing Map - Bivariate map of Alachua County property parcels using public, private, and mixed infrastructure. Parcels shown in pink use both public drinking water and public sewers. Parcels shown in green have private wells and private septic tanks. There are over 18,000 parcels shown in yellow that use a combination of public and private infrastructure but the relationship cannot be determined using this type of mapping. 


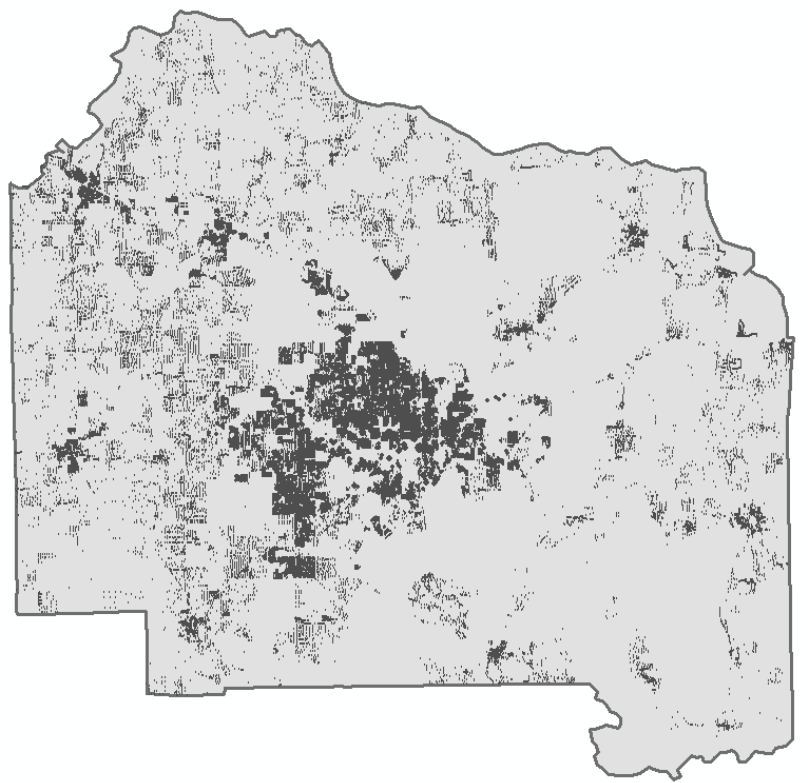

Figure 4. Population estimates for land parcels. Large circles indicate high population and smaller circles represent lower population.

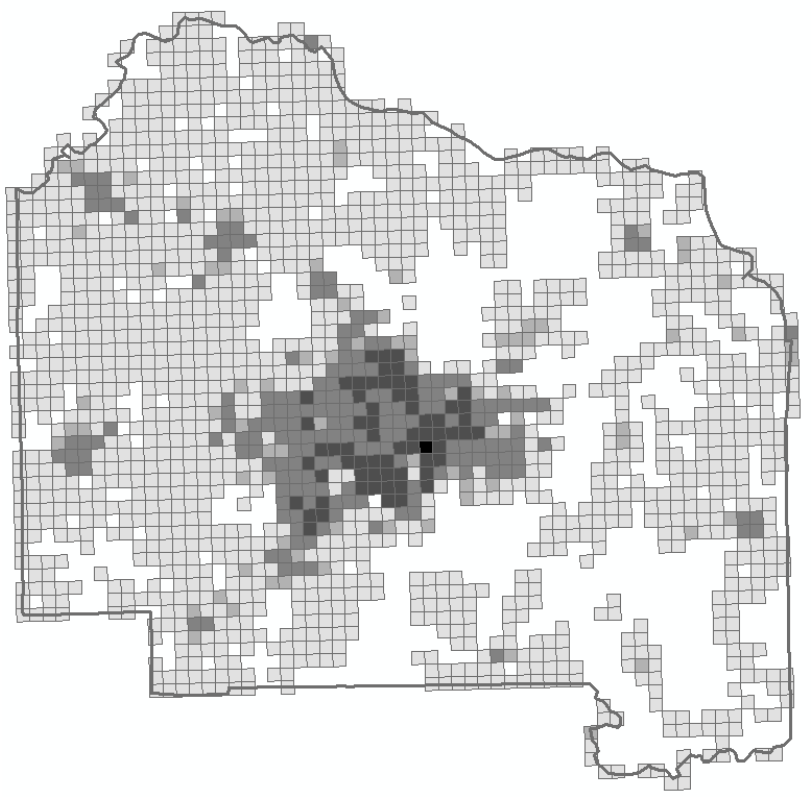

Figure 5. Population estimates aggregated to a 1-km grid system (USNG, 2020). Darker cells have higher population and lighter cells have lower population. White areas are uninhabited.

\subsection{Method}

First, the water infrastructure data (shown in Figures 1 and 2) were superimposed onto gridded population data (Figure 5). Each resulting grid cell contains the total population for the grid and the population totals using each type of water infrastructure. Second, the gridded totals were categorized into nine groups suitable for a bivariate map using a $3 \times 3$ matrix to represent categories of data interactions. The equal interval data classification method was used so that each data category represents one third of the data for both drinking and wastewater infrastructures. Third, the gridded data were converted to centroids to facilitate visualization using points instead of polygons. Fourth, the points were symbolized using both color and size. The colors selected were based upon Trumbo's (1981) 'corner' and Brewer's (1994) 'diverging/diverging' methods (Strode et al, 2020). The color pink was selected to represent both public infrastructures based upon traditional land use and land cover color palettes where pink represents development or commercialization (Jeer and Bain, 1997; USGS, 2006). The population of each grid is represented by three symbol sizes, where the size correlates to the grid's population density. Figure 6 shows the legend used for the maps.

\section{Percent of Population per 1-km Grid Using Public and Private Water Infrastructure}

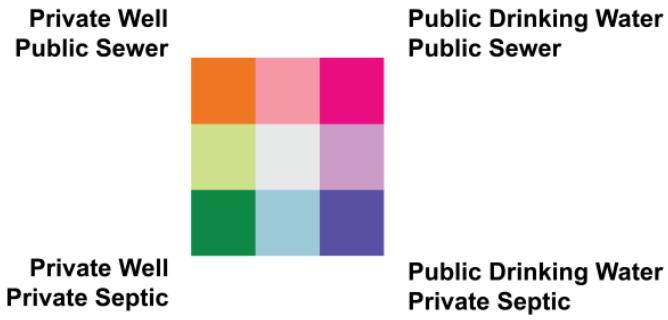

Figure 6. The legend shows the percent of population using each type of water infrastructure.

\section{Demonstration}

Our bivariate maps visualize multiple types of information from the original datasets simultaneously. The symbols use color to show the degree of population using each infrastructure type, and size to indicate the overall population. Thus, areas of high population are prominent due to the large symbol size and, similarly areas of low population are less conspicuous with smaller symbols. Unpopulated areas are distinguishable by their lack of a symbol. The color indicates the percent of population within each grid cell that uses each infrastructure. Urban areas are likely to use public drinking and wastewater and are shown in pink. Rural areas (green) might use private wells and septic systems. Some areas will use a combination of public and private infrastructure.

We demonstrate nine maps in Florida to capture a variety of population densities and infrastructure configurations. Figure 7 shows a composite overview map of the areas used for demonstration. Figures 8 through 16 are maps of selected areas shown in Figure 7. The selected areas represent the state of Florida geographically and are a sampling of rural and urban areas. The scale of the maps and the geographic area can alter the appearance of the maps slightly. Thus, our maps use scales between 
$1: 300,000$ to $1: 750,000$ and a variety of geographic areas ranging from a small city to multiple counties.

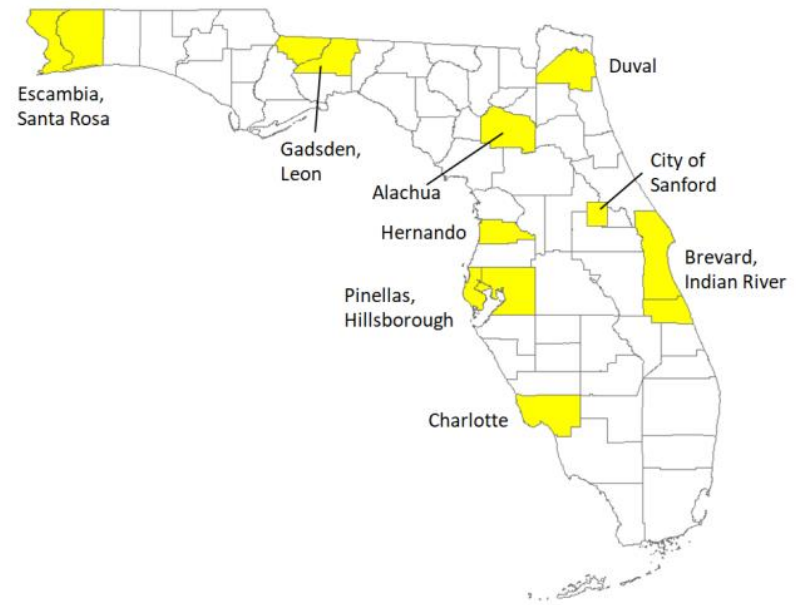

Figure 7. Overview map of the sample areas.

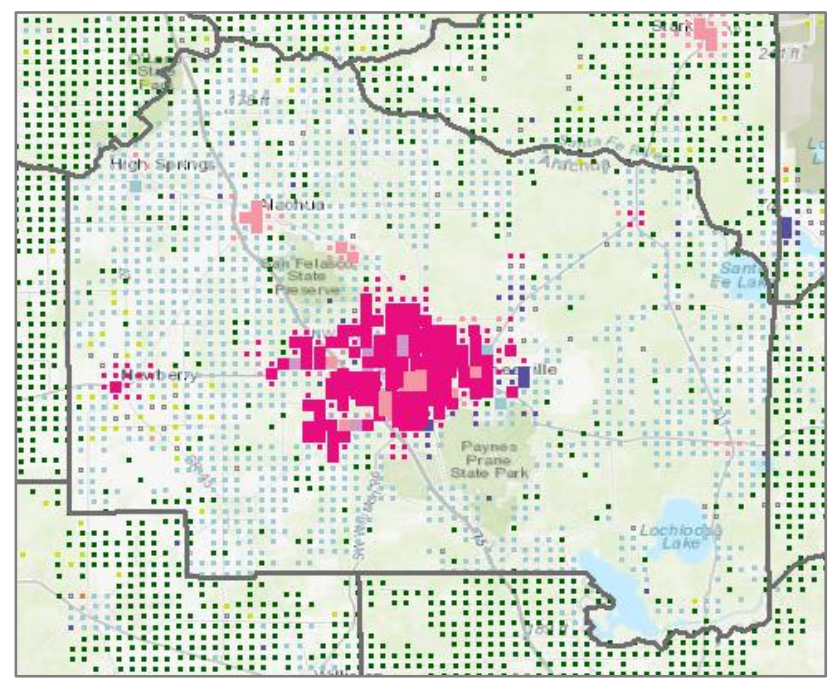

Figure 8. Alachua County. The medium blue indicates a mix of public and private infrastructures. Compare to Figures 1 through 5. Scale is $1: 600,000$

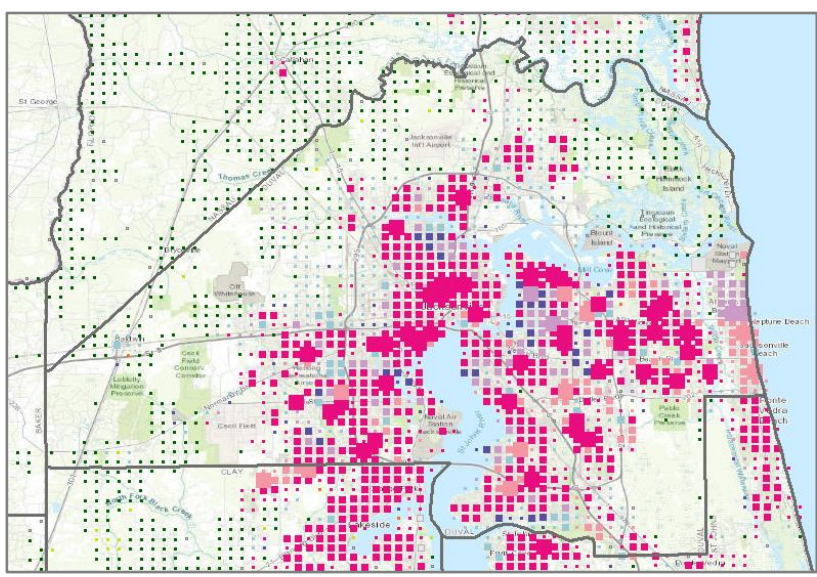

Figure 9. Duval County (Jacksonville). The dark blue symbols illustrate pockets of private septic systems located within primarily urban areas using public infrastructures. Scale is $1: 400,000$.

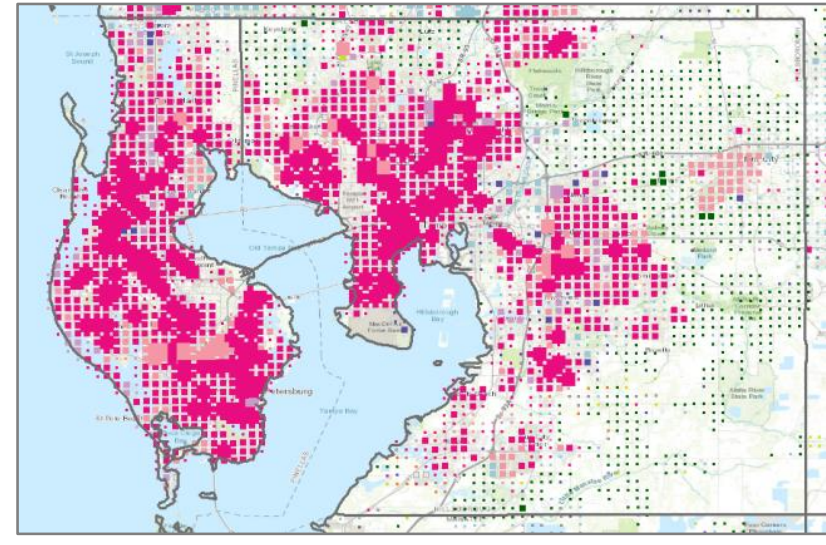

Figure 10. Pinellas (St. Petersburg) and Hillsborough (Tampa) Counties. There is an expected distinction between urban areas using mostly public infrastructures and rural areas using mostly private. Scale is $1: 400,000$.

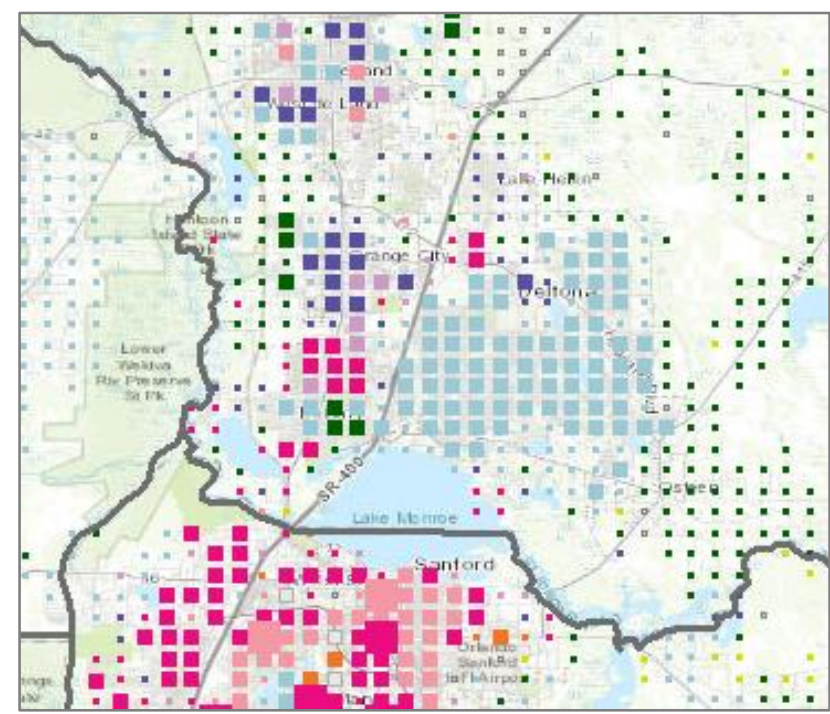

Figure 11. City of Sanford and vicinity. The population density is moderate to low with a variety of infrastructure combinations. Scale is $1: 400,000$.

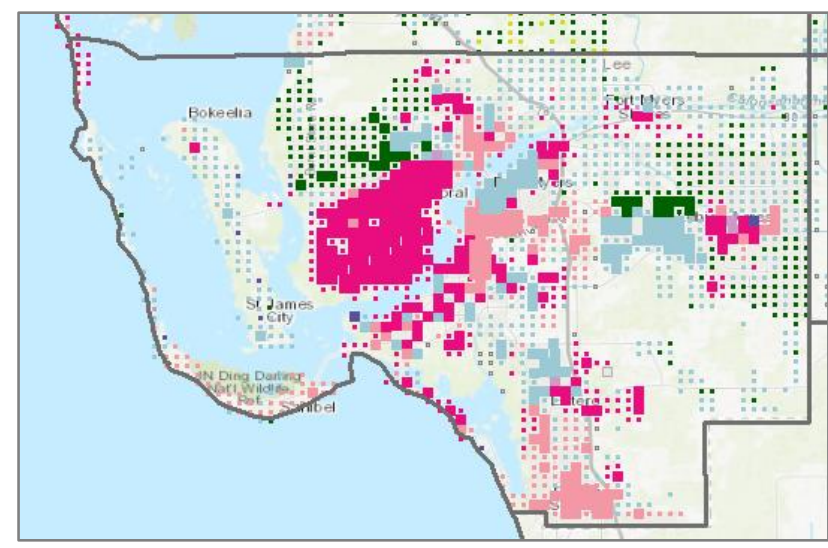

Figure 12. Charlotte County. Clearly defined urban areas use public infrastructure and other defined areas use a combination of methods. Scale is 1:600,000. 


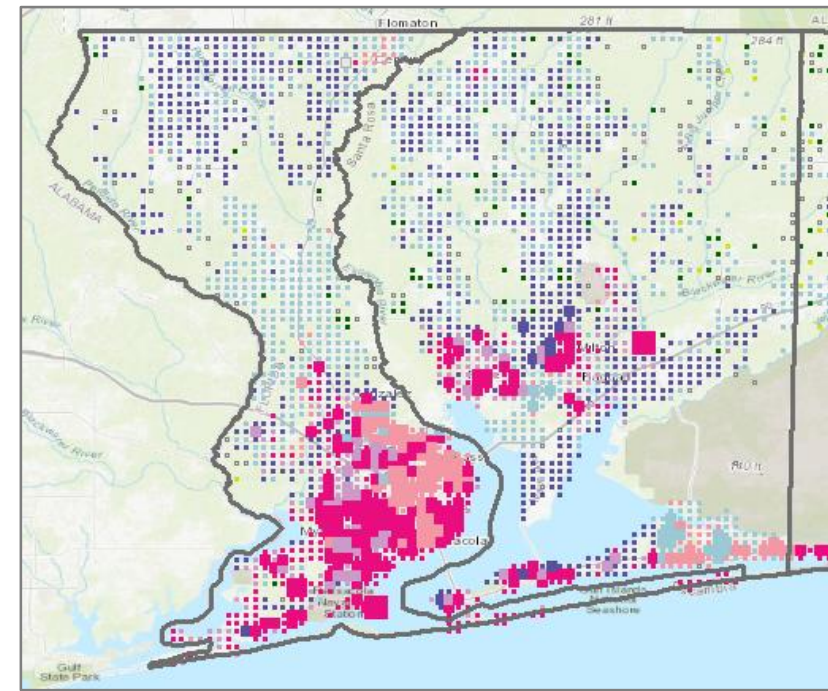

Figure 13. Pinellas (Pensacola) and Santa Rosa Counties. The populated areas use public infrastructure and the rural areas toward the north appear to use public drinking water and private septic. Scale is 1:750,000.

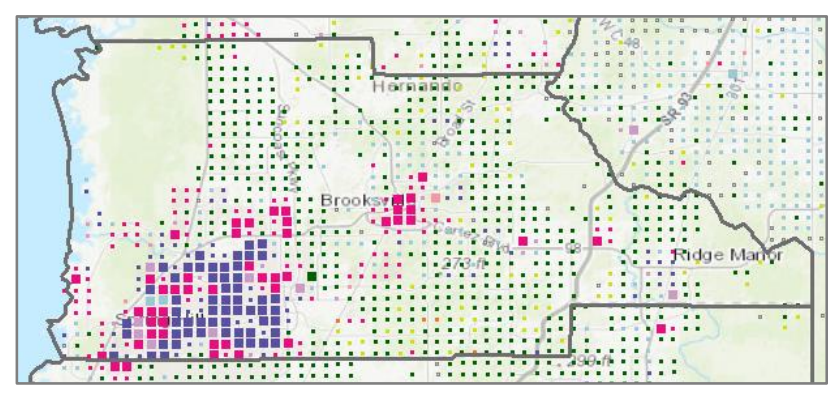

Figure 14. Hernando County. The more populated areas appear to use a mix of sewer and septic, and the lesser populated areas use mostly private infrastructure. Scale is $1: 450,000$.

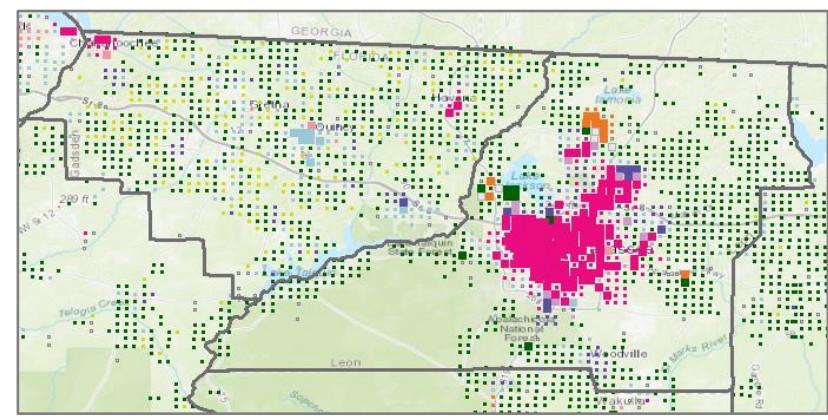

Figure 15. Gadsden and Leon (Tallahassee) Counties. Populated areas use public infrastructure and lesser populated areas can use a combination of public drinking and private sewer. The orange symbols in northern Leon County illustrate an unusual combination of private drinking wells and public sewer system. Scale is $1: 600,000$.

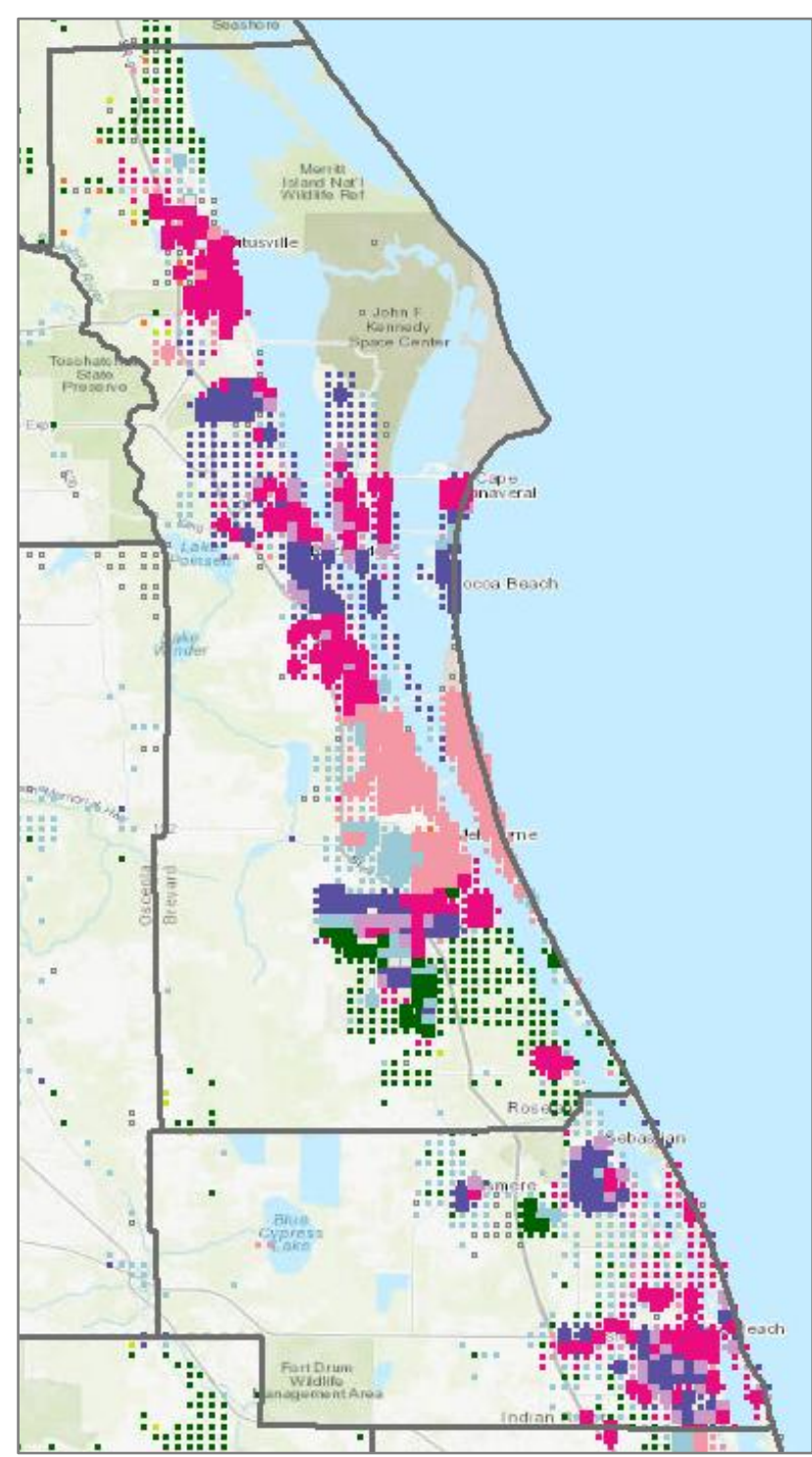

Figure 16. Brevard (Kennedy Space Center) and Indian River Counties. Note a patchwork of infrastructure combinations with a range of population densities. Scale is 1:750,000.

\section{Conclusion}

In conclusion, the bivariate maps adequately convey the population density using public and private infrastructure for both drinking and wastewater. They show that individual counties provide public services in different spatial patterns. These bivariate maps can supplement the original univariate maps showing land parcels. Planners, city officials, environmentalists, and others can benefit from bivariate maps if they were made publicly available. Our method reduces the need for multiple maps.

The techniques described here can be reproduced in any geographic area where water infrastructure and population data are available. 


\section{Acknowledgements}

The authors would like to recognize Elke Ursin, Liz Sabeff, and Michael Mitchell of the Florida Department of Health, Florida Water Management Inventory for their dedicated efforts in gathering and managing the water infrastructure data.

\section{References}

Brewer, C. A. (1994). Color Use Guidelines for Mapping and Visualization. In Modern Cartography. Vol. 2: Visualization in Modern Cartography, edited by Alan M. MacEachren and D. R. Fraser Taylor, 123-147. New York: Elsevier Science, Inc. https://doi. org/10.1016/B978-0-08-042415-6.50014-4.

Florida Water Management Inventory Project. http://www.floridahealth.gov/environmentalhealth/onsite-sewage/research/FLWMI/. [accessed 28 January 2021].

Jeer, S. and Bain, B. (1997). Traditional color coding for land uses, Report - American Planning Association.

Spier, C. and Stephenson, K. (2002). Does Sprawl Cost Us All?: Isolating the Effects of Housing Patterns on Public Water and Sewer Costs. Journal of the American Planning Association, 68:1, 56-70. 10.1080/01944360208977191

Strode, G., Mesev, V., and Maantay, J. (2018). Improving Dasymetric Population Estimates for Land Parcels: Data Pre-processing Steps. Southeastern Geographer, 58:3, p. 300-316.

Strode, G., Morgan, J.D., Thornton, B., Mesev, V., Rau, E., Shortes, S., and Johnson, N. (2019). Operationalizing Trumbo's Principles of Bivariate Choropleth Map Design. Cartographic Perspectives, 94.

Trumbo, B. E. (1981). A Theory for Coloring Bivariate Statistical Maps. The American Statistician 35 (4): 220 226. https://doi.org/10.1080/00031305.1981.10 479360.

U.S. National Grid Information Center. Data. https://usngcenter.org/portfolio-item/usng-gis-data.

Accessed March 13, 2020. 